\title{
Notas sobre el uso del helecho Jokome (Adiantum pulverulentum L. Pteridaceae) por el pueblo Murui-Muina "uitoto" en el piedemonte andino-amazónico de Colombia
}

\author{
Eider Bladimir Ortiz-Andoke (Q.E.P.D.) ${ }^{1}$, Lizhet Soto² ${ }^{2}$ David Sanín ${ }^{3, *}$ \\ ${ }^{1}$ Programa de Biología, Facultad de Ciencias Básicas, Universidad de la Amazonia, Florencia-Caquetá, Colombia \\ ${ }^{2}$ Parque Nacional Natural Alto Fragua Indi Wasi, Sistema de Parques Naturales Nacionales de Colombia, \\ San José del Fragua, Caquetá, Colombia \\ ${ }^{3}$ Herbario BHCB, Instituto de Ciências Biológicas, Departamento de Botânica, \\ Universidade Federal de Minas Gerais, Belo Horizonte, Minas Gerais, Brasil
}

\begin{abstract}
Resumen
Se describen y discuten los usos rituales, medicinales y tradicionales que el pueblo Murui-Muina, registra para el helecho Jakome (Adiantum pulverulentum L.) Pteridaceae. (C) 2018. Acad. Colomb. Cienc. Ex. Fis. Nat.

Palabras clave: Adiantum; Baile de la Fruta; Convergencia cultural; Peligro de extinción; Etnopteridología.

Notes about the use of the fern Jokome (Adiantum pulverulentum L. Pteridaceae) by the people Murui-Muina "uitoto" in the Foothill Andean-Amazonic of Colombia
\end{abstract}

\begin{abstract}
The traditional, medicinal and ritual uses that the people Murui-Muina, register for the fern Jakome (Adiantum pulverulentum L.) Pteridaceae are described and disscused. (C) 2018. Acad. Colomb. Cienc. Ex. Fis. Nat.
\end{abstract}

Key words: Adiantum; Fruit Dance; Cultural convergence; Extinction risk; Etnopteridology.

\section{Introducción}

El pueblo Murui-Muina es conocido erradamente en la literatura etnográfica como huitotos, uitotos o witotos, cuyo origen etimológico se estructura en los vocablos Caribes (Carijonas): "itotos", "uitotos", “quiyoyos”, o palabras similares que significan "otra gente" (Griffiths, et al., 1998). Esta nominación fue designada por los grupos Huaque que utilizaban dichos vocablos para las personas que capturaban en el desarrollo de sus luchas interétnicas, el cual posteriormente fue utilizado por los españoles en la conquista (Pineda, 1987), y prevalece en la actualidad. Esta denominación en referencia es ajena a la propia designación cultural que hoy hacen los Murui-Muina (los hijos de la coca, el tabaco y la yuca dulce).

De acuerdo con el lugar geográfico que ocupa cada grupo de la cultura Murui-Muina, es posible distinguir cuatro dialectos relacionados y mutuamente inteligibles: Bue, Mika, Minika y Nipode (Griffiths, et al., 1998). Sin embargo, la zona interfluvial del Caquetá y el Putumayo conforman el centro del territorio ancestral Murui-Muina (Griffiths, et al., 1998).

Se registran 6.444 personas pertenecientes a la cultura Murui-Muina (Censo del Ministerio del Interior, 2015), con un alto riesgo de extinción física y cultural (Corte
Constitucional de Colombia, 2009). Las comunidades Muina en situación de desplazamiento forzado en la ciudad de Florencia (capital del departamento del Caquetá) han utilizado el dialecto Nipode como estrategia de supervivencia cultural.

Para esta cultura, la botánica o la "carrera de las plantas" representa el estudio de los organismos vegetales desde un sentido amplio y complejo, el cual abarca el conocimiento de cada estructura, sus usos y el potencial que cada órgano presenta según su fenología y la manera en que se utilice al combinarlo con otras especies. De esta forma, en armonía con las labores y los roles que cada hombre y mujer cumple en el grupo, los Muina realizan rituales intrínsecamente relacionados con la naturaleza, donde las plantas tienen un papel fundamental como lo demuestran los usos seculares y rituales de la coca o "Jibie" (Erythroxylum coca Lam.), el tabaco o "Diona" (Nicotiana tabacum L.) y la yuca dulce o "Pareka" (Manihot esculenta Crantz), entidades sagradas que cumplen un papel determinante en la ordenación y equilibrio del mundo.

*Correspondencia:

David Sanín,dav.sanin@gmail.com

Recibido: 19 de diciembre de 2017

Aceptado: 31 de marzo de 2018

Editor: Elizabeth Castañeda 
Con el objeto de potenciar dichas entidades, el pueblo Muina suele utilizar diversos taxones en sus rituales, ya sea para agradecer por los frutos de la tierra, promover la fertilidad en la cosecha, favorecer la salud, curar la enfermedad, e incrementar la suerte o la sabiduría en la caza. Es aquí, donde los helechos adquieren un papel fundamental.

No obstante, su abundancia y diversidad en Colombia (Murillo, et al., 2008), los helechos son un grupo poco estudiado, y menos aún descrito en rituales realizados por los pueblos indígenas (Murillo, 1983; May, 1978; Keller \& Prance, 2015)

Derivado de la experiencia del primer autor como miembro del pueblo Muina, se describen y comentan los usos que su cultura registra para el "Jokome": Adiantum pulverulentum L. (Pteridaceae) (Figura 1), en el asentamiento El Manantial, ubicado a los alrededores de la ciudad de Florencia, Caquetá, Colombia $\left(1^{\circ} 36^{\prime} 51^{\prime \prime} \mathrm{N}, 75^{\circ} 36^{\prime} 42^{\prime \prime} \mathrm{O}\right)$, a una altura promedio de $242 \mathrm{~m}$.

\section{Uso ceremonial}

El Jokome es utilizado en los bailes rituales Yuaki, Rafue o baile de la fruta y Tikida Buinaima o baile de cacería. En este aporte, se hará énfasis en el baile Yuaki y canto de Muiruiki, el cual representa una tradición que despliega el conocimiento de los ciclos estacionales, la historia natural de los frutos silvestres, las interacciones sociales entre invitados y los dueños de la maloca, y el papel de hombres y mujeres en la producción de los alimentos y el ejercicio ceremonial (Candre, 2011). El baile ritual de Yuaki o baile de la fruta, es practicado en la actualidad por los Muina como uno de los cuatro bailes pilares fundamentales en el proceso de formación de un cacique o dueño de maloka, el cual es correspondiente al "pilar de la abundancia". En este ritual se agradece a la madre tierra "Buinaima" por la cosecha y los frutos recibidos, los dueños de la maloka preparan y comparten grandes cantidades de comida cultivada (principalmente yuca y sus derivados), Ambil de tabaco o "Rogoki" y Mambe de coca o "Jibie", con los que reciben y pagan los cantos, las frutas silvestres y la cacería que deben traer los invitados (Candre, 2011). En la realización del baile de la fruta, el helecho Jokome (Adiantum pulverulentum) es fundamental para marcar el ritmo del mismo y como su ambientador. Para su utilización se toma un manojo de hojas secas amarradas y compactadas de Jokome (Figura 2), para ser agitadas según el ritmo del canto, generando un sonido característico, que según nuestra narración, es utilizado en un punto especial de la ceremonia para estabilizar y filtrar la energía. Es considerado como un catalizador de las buenas energías, dado que para los Muina, su aroma no permite identificar al individuo de los malos espíritus, ni del olfato de los animales, reconociéndosele como un aromatizante. Al respecto, May (1978) comenta que algunas especies de helechos, dentro de las que se encuentran Adiantum capillus-veneris L., especie relacionada con el Jokome, presentan constituyentes que incluyen ácido tánico, ácido gallico y trazas de aceites esenciales, lo cual puede producir un olor plácido tónico.

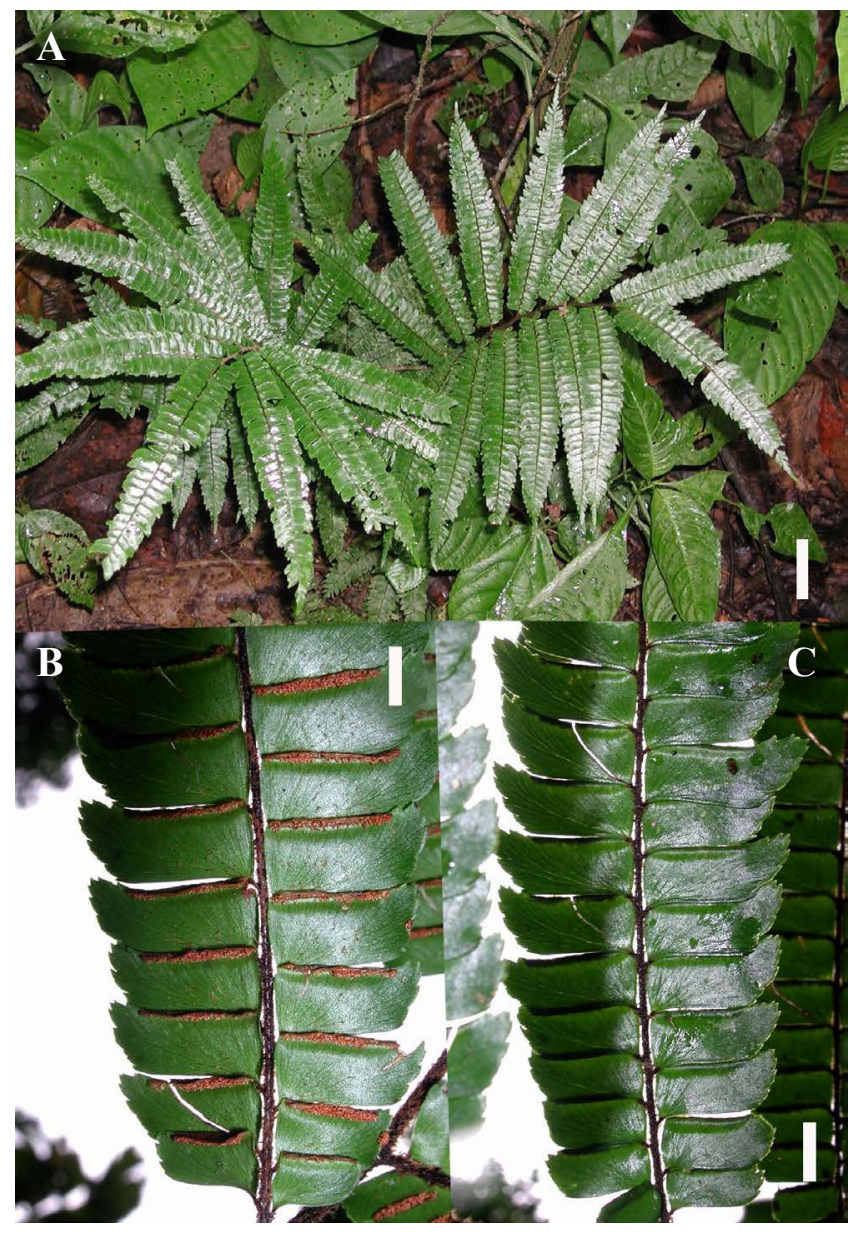

Figura 1. Jokome o Adiantum pulverulentum L. (Pteridaceae). (A). Hábito de la planta. (B). Superficie abaxial donde se observa el detalle de los soros lineares. (C). Superficie adaxial. Escalas: (A). 7 cm. (B). $1 \mathrm{~cm}$. (C). 7 mm. Fotos por R.C. Moran.

La trascendencia de la ceremonia Yuaki para el pueblo Muina, y el uso del helecho Jokome (Adiantum pulverulentum) en un punto especial de ella, estimula la generación de interrogantes sobre el entendimiento que los Muina tienen sobre las plantas: ¿Los Muina reconocen la diferencia evolutiva entre los helechos y las angiospermas?, de ser así, ¿Esta diferencia trasciende lo espiritual y determina una neutralidad en su ofrenda a la madre tierra?, ¿Por qué utilizan un helecho y no una planta con flores para agradecer por la cosecha de frutos y semillas?

\section{Uso medicinal}

En la medicina tradicional del pueblo Muina, el Jokome es de gran importancia ya que es utilizado en diferentes tratamientos.

1) Dolor de cabeza y gripe: para esto se recolectan las hojas nuevas, luego se maceran a mano y posteriormente el curaca o médico tradicional "ikoriraima" debe narrar la oración, para que el paciente pueda inhalar el vapor del hervido entre 30 minutos a una hora y durante una semana. 


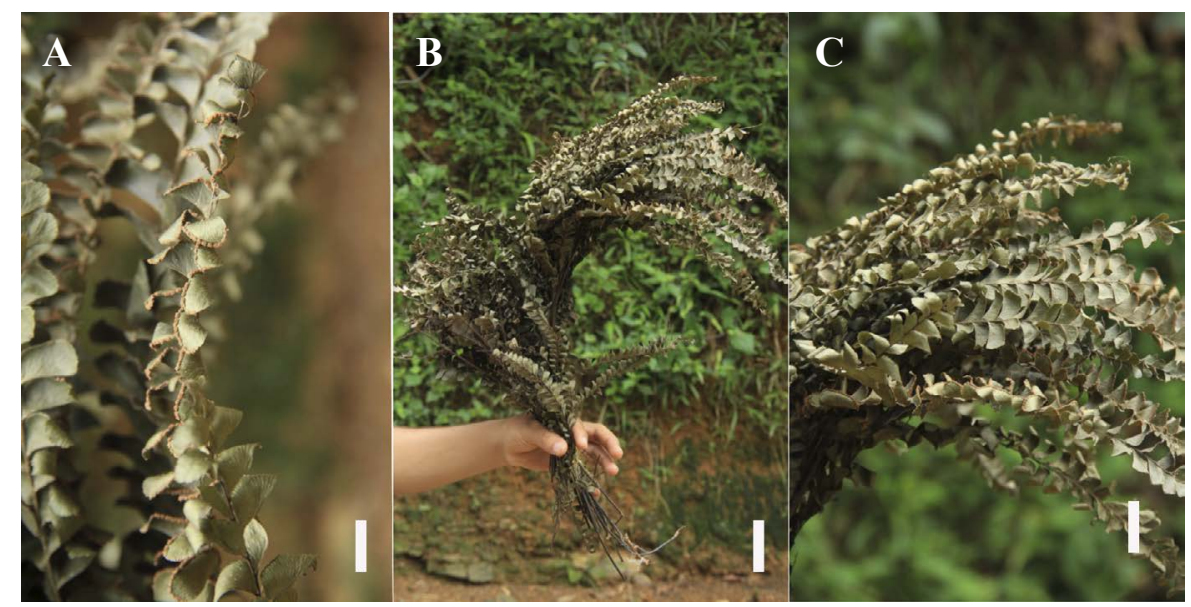

Figura 2. Manojos de Jokome o Adiantum pulverulentum L. (Pteridaceae), utilizados en el baile de la fruta. (A). Detalle de una pinna fértil. (B). Manojo completo de Jokome. (C). Ápice del manojo de Jokome. Escalas: (A). 7 mm. (B). 5 cm. (C). 5 cm. Fotos por J.L. Peña.

En este sentido, otras especies del género Adiantum (vg. A. aethiopicum L., A. capillus-veneris L. y A. caudatum L.) fueron utilizadas por los herbalistas para curar un vasto número de enfermedades y son útiles en el tratamiento de fiebres, la gripe y enfermedades relacionadas (Lloyd, 1964; May, 1978).

2) Fiebre: se recolectan y depositan las hojas nuevas en un recipiente con agua hervida, posteriormente se hacen rezar por el curaca para después suministrar una porción (200-250 mm) al paciente. Este tratamiento debe realizarse dos veces al día durante una semana. May (1978) comenta que $A$. capillus-veneris es el principal ingrediente del famoso "Sirope de Capillaire", ampliamente utilizado para calmar la fiebre en Francia.

3) Disminución del envejecimiento: se recolectan las mejores y más jóvenes hojas, luego se depositan en un recipiente con agua para que posteriormente sean rezadas por el curaca. Luego se procede a realizar baños donde las hojas del Jokome se deben distribuir con presión por todo el cuerpo, provocando que la persona se libere de la energía negativa que carga y mantenga así su juventud. Al respecto, Keller \& Prance (2015) mencionan la existencia de substancias con actividad antioxidante en diversos helechos, las cuales son utilizadas en la medicina para reducir el estrés producto de la oxidación, entre ellos, un familiar del jokome, Adiantum capillus-veneris podría citarse como ejemplo (Kumar, 2009).

\section{Uso ritual para la cacería}

Existe además un uso ritual que el pueblo Muina determina para el helecho Jokome, con el cual se pretende incrementar el éxito en una actividad que es exclusiva de los hombres, la cacería. Para esto, se recolectan las vernaciones circinadas (hojas jóvenes no desarrolladas del helecho), que posteriormente se maceran a mano, distribuyéndolas con presión por todo el cuerpo antes de salir a cazar. Esto permite que los animales no perciban al cazador, o que no logren registrar su olor, lo cual puede ser explicado por algún tipo de mimetismo generado por el olor de la planta, y a su vez indica una lógica legendaria explorada y utilizada por los Muina que evoca una antigua idea Europea Cristiana descrita por Paracelsus (1493-1541) como "la doctrina de las asignaturas, teoría del signo, o de las asignaturas", a partir de la cual en el medioevo se combinó la medicina y la astrología con la botánica y la superstición, determinando que la naturaleza de las formas, colores, sabores, olores y otros atributos particulares de las plantas (hojas y flores, etc.), podrían indicar su utilidad, especialmente para controlar enfermedades (Pearce, 2008). Sin embargo, para los helechos, dadas sus complejas arquitecturas foliares, su grado de disección laminar, y sobre todo, su enigmática e inconspicua reproducción por esporas, la cual, debido al tamaño de las mismas (30 y $100 \mathrm{~m} \mu$ ) Tryon \& Lugarton (1990), fue imperceptible para el ojo humano de la época. A la luz de esta doctrina, se podría asumir que los helechos representaban plantas desconocidas, enigmáticas, y hasta relacionadas con la magia y brujería. Se generó así una fijación por el desconocimiento de las estructuras reproductivas de los helechos y al relacionarlos con las plantas con semillas, se asumió que sus semillas eran invisibles (Moran, 2004), y por lo tanto, todo aquel que tuviera el privilegio de poseerlas, adquiría dicho atributo (Duran, 1949). Las etnias Celtas y Germanos concluyeron que estas plantas otorgaban este privilegio, debido a que estas plantas crecían e incrementaban sus poblaciones sin ningún órgano reproductor aparente (Friend, 1884), considerándolas como una sagrada fuente de poder (May, 1978).

Por los argumentos anteriormente citados es posible que el pueblo Murui-Muina, por la aparente ausencia de estructuras reproductivas (frutos o semillas), la ecología de la planta -ubicada principalmente en zonas abiertas e intervenidas- y sobre todo, por el continuo contacto con Adiantum pulverulentum, haya considerado relacionar que la especie brindaba ventajas a la persona que la utiliza 
en la caza y la lucha, ya que al nunca observar sus frutos o semillas, podía tratarse de una planta que promovía la invisibilidad.

Este hecho representa un interesante ejemplo de convergencia cultural, donde el ser humano más allá de sus barreras culturales, al relacionarse con su entorno natural, se ha provisto de los helechos, para defenderse, curarse, vestirse, alimentarse, y por ser estos tan importantes en su evolución, los han revestido con un halo de magia.

\section{Agradecimientos}

A la comunidad Murui-Muina del Corregimiento del Manantial, Florencia, Caquetá, por su amable acogida. A Robbin C. Moran (NY) y Jorge L. Peña (SIBE), por sus fotografías. Agradecemos a Elizabeth Castañeda y a dos evaluadores anónimos por sus valiosos comentarios. A la Universidad de la Amazonia por el apoyo logístico. Este aporte es dedicado a la memoria de nuestro colega botánico y medico tradicional Muina Eider Bladimir Ortiz Andoque.

\section{Contribución de los autores}

EBOA, LS y DS diseñamos y escribimos el manuscrito.

\section{Conflicto de intereses}

Los autores manifiestan no tener conflictos de intereses.

\section{Referencias}

Candre Yamakuti, A. (2011). Mooma Mogorotoi yoga rafue: Yuai Buinama uai ikaki monifuena ari kaimo monoiya, okaina imaki dibinedo. Mundo Amazónico. 2: 307-327.

Corte Constitucional de Colombia. (2009). Auto 009/09. Fecha de consulta: 10 de diciembre de 2017. Disponible en: http:// www.corteconstitucional.gov.co/relatoria/autos/2009/ a004-09.htm
Durand, H. (1949). Field Book of Common Ferns. G. P. Putnam's Sons, N.Y.

Friend, H. R. (1886). Flowers and Flower Lore. Swan Sonnenschein and Co., London.

Griffiths, T., Coleman, J., \& Morales, M. (s.f.). Un léxico Nipode uitoto - español - inglés. Oxford: Universidad de Oxford.

Keller, H.A. \& G.T. Prance. (2015). The ethnobotany of ferns and Lycophytes. Fern Gazette. 20: 1-13.

Kumar, A. (2009). Antioxidant effect of Adiantum capillus veneris Linn. on human lymphocyte: an in vitro study. Journal of Cell and Tissue Research. 9: 1899-1902.

Lloyd, R. M. (1964). Ethnobotanical Uses of California Pteridophytes by Western Indians. American Fern Journal. 54: 76-82.

May, L. (1978). The economic uses and associated folklore of ferns and ferns allies. The Botanical Review. 44: 491-528.

Ministerio del Interior. (2015). Pueblo Uitoto. Bogotá: Ministerio del Interior.

Moran, R. C. (2004). A Natural history of ferns. Timber Press. Portland, Oregon, Estados Unidos. 301 pp.

Murillo, M.T. (1983). Usos de los helechos en Suramérica con especial referencia a Colombia. Ed. Instituto de Ciencias Naturales, Biblioteca José Jerónimo Triana, No 5, 156 pp. Bogotá.

Murillo, M. T., J. C. Murillo-A. \& A. León-Parra. (2008). Los Pteridófitos de Colombia. Editorial ARFO Ltda. Bogotá.

Pearce, J. M. S. (2008). The doctryne of signature. European Neurology. 60: 50-51.

Pineda, R. (1987). "Witoto". En: R. Pineda (ed.), Introducción a la Colombia Amerindia, pp. 151-164. Bogotá: Instituto Colombiano de Antropología.

Tryon, A. F., \& Lugardon, B. (1991). Spores of the pteridophyta. Surface, wall structure, and diversity based on electron microscope studies. New York: Springer-Verlag Inc. 